\title{
REPRESENTAÇÕES DE GUERRA NAS PINTURAS RUPESTRES DA SERRA DA CAPIVARA, PI, BRASIL
}

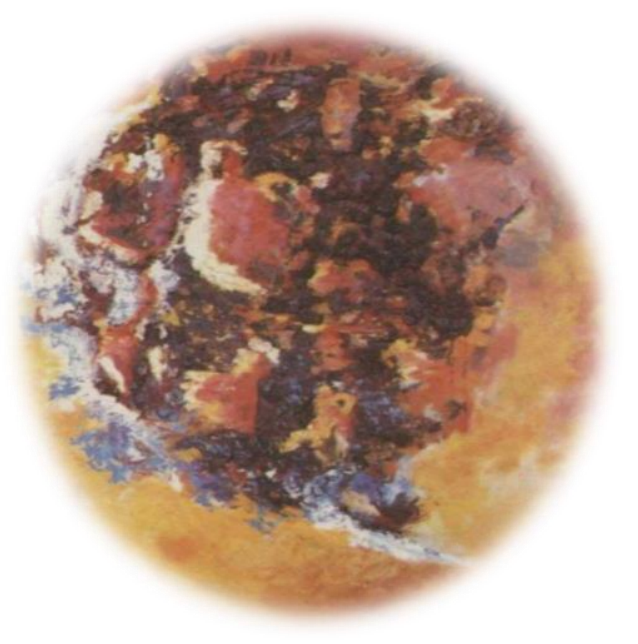

Vanessa da Silva Belarmino', Michel Justamand, Gabriel Frechiani de Oliveira ${ }^{3}$ Pedro Paulo A. Funari ${ }^{4}$

\section{Resumo}

As primeiras pesquisas arqueológicas realizadas na área do Parque Nacional Serra da Capivara, sudeste do Piaú-Brasil, iniciaram-se na década de 70, conduzidas pela arqueóloga Niède Guidon, com o objetivo de contextualizar os sítios com grafismos rupestres, resultando em um ordenamento prévio hipotético para um reconhecimento das

${ }^{1}$ Geógrafa - UESPI, Guia de Turismo - IFPI, Especialista em Geografia - FLATED, Especialista em Geoturismo e Graduanda em Arqueologia e Preservação Patrimonial UNIVASF. Rua Avelino José Negreiros, 221, Bairro Umbelina, São Raimundo Nonato - PI. CEP 64770-000. Email: vanessabela18@hotmail.com

${ }^{2}$ Graduado e Licenciado em História, Mestre em Comunicação e Semiótica, Doutor em Antropologia e Pós-Doutor em História, todos pela PUC/SP. Docente da Universidade Federal do Amazonas - UFAM, lotado no Instituto de Natureza e Cultura - INC, unidade acadêmica de Benjamin Constant. Professor Permanente no Programa de PósGraduação em Sociedade e Cultura na Amazônia - PPGSCA da UFAM, em Manaus. Endereço: Rua General Julio Marcondes Salgado, 65, apto 52, Campos Eliseus, São Paulo -SP. CEP 01201-020. Email: micheljustamand@yahoo.com.br ${ }^{3}$ Historiador - UESPI. Doutorando em Arqueologia - UFS. Universidade Federal de Sergipe, Campus Laranjeiras , Sergipe. Email: gfrechiani@hotmail.com ${ }^{4}$ Professor Titular do Departamento de História da Unicamp. 


\title{
REPRESENTAÇÕES DE GUERRA NAS PINTURAS RUPESTRES DA SERRA DA CAPIVARA, PI, BRASIL
}

identidades culturais e cronologias. A definição classificatória de Tradição parte das semelhanças tipológicas que são encontradas entre os grafismos. Nas pesquisas, os grafismos rupestres são considerados como um meio de comunicação que seguem um código pré-estabelecido. O comportamento agressivo e violento pode ser identificado no registro arqueológico em aldeias destruídas, tais como esqueletos humanos com marcas de fraturas e na gestualidade representada nos grafismos rupestres. Nosso artigo se refere a uma pesquisa em andamento e tem por objetivo a identificação de padrões gráficos presentes nas cenas de guerra e, como objetivo específico, a identificação de elementos reconhecíveis, como antropomorfos, objetos de usos e outros possíveis atributos culturais. Parece-nos que entre os grupos primitivos, o comportamento agressivo e violento poderia ocorrer por diversas motivações, obedecendo a ritos culturais, conflitos entre grupos, ou ainda, a aquisição de recursos essenciais para a sobrevivência do grupo.

Palavras-chave: Grafismos rupestres, Cenas de guerra, Serra da Capivara - PI.

\begin{abstract}
The first archaeological investigations carried out in the Serra da Capivara National Park, southeastern Piaui-Brazil, began in the 70's conducted by the archaeologist Niède Guidon, with the aim of contextualizing the sites with rock paintings, resulting in a hypothetical prior arrangement for a Recognition of cultural identities and chronologies. The classificatory definition of Tradition starts from the typological similarities that are found between the graphisms. In research, rock art is considered as a means of communication, in which it follows a pre-established code. The behavior of aggressive and violent can be seen in the archaeological record in destroyed villages, human skeletons with marks of fractures and in the gestuality represented in rock drawings. The research aims at identifying graphic patterns present in war scenes, and as a specific objective the identification of recognizable elements, such as anthropomorphs, objects of use, and cultural attributes. In the primitive groups, aggressive and violent behavior had diverse Motivations, cultural obeisances, conflicts between groups, or acquisition of essential resources for the survival of the group.
\end{abstract}

Keywords: Rock paintings, Scenes of war, Serra da Capivara - PI.

\section{Introdução}

As pesquisas arqueológicas na área da Serra da Capivara, localizada no sudeste do estado do Piauí, tiveram início na década de 1970. Por ausência de um contexto arqueológico definido, os trabalhos de campo buscaram identificar os sítios com pinturas e gravuras rupestres. Estes foram os primeiros vestígios préhistóricos estudados na região. Com o desenvolvimento das pesquisas, foram elaboradas classificações e cronologias para os grafismos rupestres. 
Os grafismos rupestres, como objetos da pesquisa arqueológica, apresentam informações das populações que habitaram na área no passado. Eles são testemunhos dos comportamentos culturais de seus autores e servem, parecenos, de base para compreensão da dinâmica sociocultural dos grupos, no âmbito de uma visão simbólica e cognitiva.

As pesquisas já realizadas no Parque Nacional Serra da Capivara apontam que os grafismos rupestres seriam formas de comunicação daqueles grupos humanos. Funcionavam como um sistema de códigos de linguagem que transmite informações sobre as transformações e representações sociais do mundo sensível dos grupos humanos. Pensamos à semelhança de Pessis,quando argumenta que "mesmo que um significado não seja compreendido, a obra rupestre pré-histórica permite inferir a diferentes culturas" (PESSIS 2003).

$\mathrm{Na}$ região Nordeste do Brasil, os registros rupestres foram analisados e classificados em categorias. A categoria inicial é a Tradição, que envolve padrões gráficos de forma mais geral. Na sequência, a Subtradição, que é caracterizada por traços temáticos e de apresentação em uma área geográfica específica. Dentro da Subtradição, pode ser definida a classe de Estilo, que corresponde a mudanças técnicas e temáticas. No presente texto, lidamos apenas com a Tradição Nordeste, Subtradição Várzea Grande, que foi realizada e desenvolvida no período de 12.000 a 6.000 anos AP. Dentre as pinturas rupestres dessa tradição, as temáticas são geralmente representações de aspectos aparentemente reconhecíveis, como as figuras humanas, animais, plantas, e também as não reconhecíveis, como as figuras com formas geométricas.

As representações reconhecíveis possuem diferentes atributos, adornos e tipos morfológicos. Os temas que poderiam ser chamados de solidários, dentro de cada comunidade, são os mais frequentes: cena da família, lúdica, da colheita e da caça, aparecendo também cenas de luta e agressão (MARTIN 1984). As pinturas da Subtradição Várzea Grande possuem representações do cotidiano. A temática de guerra é uma forma de representação de parte desse cotidiano e da complexidade dos indivíduos. Ela simboliza a vida social do grupo, caracterizada por marcadores sociais particulares que podem ser identificados na cenografia.

Justificamos essa abordagem a partir das cenas de "guerra" (Figura 1), por haver nela evidências do patrimônio natural e arqueológico que precisam ser constantemente pesquisadas e preservadas adequadamente. 


\section{REPRESENTAÇÕES DE GUERRA NAS PINTURAS RUPESTRES DA SERRA DA CAPIVARA, PI, BRASIL}

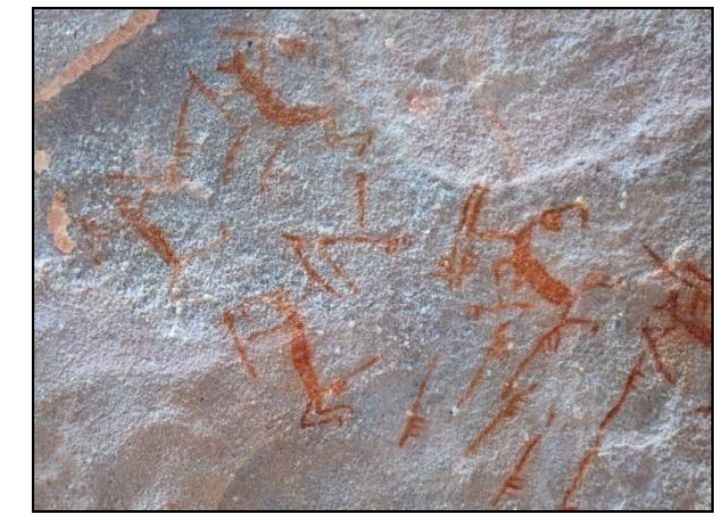

Figura 1: Cena de guerra. Toca do Conflito. Serra da Capivara. Piauí. Brasil. Fonte: Fernando Queiroz

2017

Pensamos que nossos escritos poderão, de alguma forma, contribuir com esse campo do pensamento, sobretudo a respeito da necessidade de se produzir conhecimento novo, em aspecto contínuo, sobre o passado - aspecto este fundamental para a preservação dessa modalidade de patrimônio. Temos como certo que a finalização de um trabalho, seja de pesquisa, seja de escrita, não condiz com a estagnação verificada na área, haja vista a existência de diversos vieses de continuidade. No entanto, a priori, é necessário assinalar que a sociedade, como um todo, está sujeita a perder estes bens culturais, haja vista que muitos painéis de pintura rupestre da Serra da Capivara se deterioram porque estão expostos ao vento, ao sol e à chuva, colocando em risco a proteção do patrimônio arqueológico lá existente.

Dessa forma, buscamos, nesse artigo, apresentar nossos objetivos e metodologias, a saber: o registro rupestre da região do Parque Nacional Serra da Capivara, suas categorias de análises, a temática da guerra como fator social nas cenas rupestres e algumas cenas para ilustrar os nossos intuitos.

\section{Objetivos e metodologia}

Entendemos que a arqueologia pré-histórica fornece em suas pesquisas, informações sobre os padrões comportamentais das populações humanas. Tratando-se, especialmente, dos comportamentos agressivos, descobertas etnoarqueológicas sugerem que esse comportamento é inerente à espécie humana. Agressividade e violência eram necessárias para a subsistência. Nas pinturas rupestres pré-históricas são numerosos os exemplos de figuras humanas caçando com armas, propulsores e arcos, bem como representações de combates coletivos e formas de agressão entre duas figuras humanas (PESSIS 2003). 
Partimos, dessa forma, do princípio questionador de que aparentemente existem cenas de guerra nas pinturas da Subtradição Várzea Grande. Quais seriam, então, os elementos caracterizadores suscetíveis de reconhecimento dessa temática?

Para tal, buscamos identificar os elementos reconhecíveis na representação da temática de guerra (antropomorfos e objetos de uso); buscamos, ainda, identificar sobreposições nas cenas de guerra; e, por fim, identificar padrões nos marcadores sociais (adornos, armas e outros objetos de mão) e nos grafismos antropomórficos envolvidos na cena.

Para a abordagem do presente estudo, foram selecionados os seguintes sítios: Toca do Conflito, Toca da Extrema II, Toca do João Arsena e Toca do Vento. Estes são alguns dos sítios que contêm cenas que representariam, a nosso ver, imagens associadas à guerra (Figura 2).

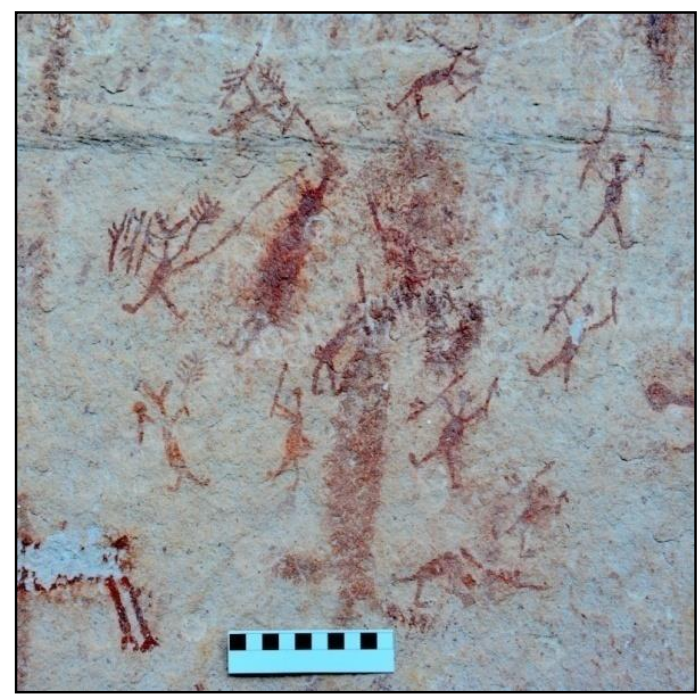

Figura 2: Cena de guerra. Toca do João Arsena. Serra da Capivara. Piauí. Brasil. Fonte Direta 2017

Para atingir tais objetivos, seguimos os procedimentos analíticos de ordem, técnica, temática e cenográfica, e também do entendimento da tradição, subtradição e estilo, tal como foi apresentado anteriormente. A dominância das pinturas reconhecíveis da Tradição Nordeste possibilita trabalhar a temática de guerra a partir dos traços essenciais de identificação.

Já a nossa metodologia foi baseada na pesquisa imagética de campo em sítios do Parque Nacional Serra da Capivara; realizamos os devidos cadastros de sítios da Subtradição Várzea Grande, com preenchimento de protocolo de levantamento de sítio; realizamos, ainda, o tratamento das imagens colhidas nos trabalhos de campo com ferramentas de softwares para coleta de informações e 


\section{REPRESENTAÇÕES DE GUERRA NAS PINTURAS RUPESTRES DA SERRA DA CAPIVARA, PI, BRASIL}

segregação dos elementos representativos; e, concluímos coma sistematização da formulação de um banco de dados, com a finalidade de organização das informações.

O levantamento imagético, além daqueles realizados em campo, foi conduzido também junto à Fundação Museu do Homem Americano, que disponibiliza um amplo acervo composto por fotografias, cópias em plásticos, dentre outros artigos imagéticos; tal pesquisa abrangeu artigos datados desde a década de 1970.

Relacionando o estudo de cadastros de sítios da Subtradição Várzea Grande com o desenvolvimento do protocolo de levantamento, nos foi possível obter informações gerais e específicas para o presente texto e para novas pesquisas que venhamos a fazer na região.

Algumas das informações arqueológicas gerais encontradas nos sítios da subtradição - como os tipos de rochas suportes, as características do ambiente, tipos de intervenções que ocorreram na área - podem contribuir para compreendermos os desejos e anseios daqueles grupos ancestrais. A disposição dos painéis também ajudou a refletir sobre as cenas observadas.

Em específico, são valorosas as informações sobre o registro rupestre, dimensão da mancha gráfica, quantidade de painéis, distância do solo, cenografia, tamanho dominante das pinturas, os tipos de cores, os tipos de sobreposições, as tradições e os estilos presentes. As informações das cenas de guerras partem da posição do painel na mancha gráfica, tipos de sobreposição, composição, dinamismo e movimento dos antropomorfos com os objetos usados na ação da cena.

O tratamento de imagem, parece-nos, tem importante contribuição para o desenvolvimento de pesquisas em arqueologia, sobretudo quando se pretende a coleta de informações minuciosas. Para o presente trabalho, a utilização de ferramentas de softwares nas pinturas rupestres possibilitou selecionar os pixels e levantar, detalhadamente, figura por figura que compõe a cena na mancha gráfica, conforme demonstrou Vialou (2006).

É importante ainda frisar que o incremento dos trabalhos de documentação dos grafismos rupestres pré-históricos por meio de tratamento de imagens digitalizadas expande o entendimento dos motivos gráficos presentes nos paredões rochosos (VILLAVERDE2002).

Há necessidade de automatização do processo de distinção entre os pigmentos do suporte, eliminando parte da subjetividade da aplicação da fotografia digital. A segregação da imagem compreende distinguir os pixels correspondentes à cor da pintura em sua impregnação no suporte rochoso, objetivando deixar mais clara a visualização da imagem do painel rupestre 


\section{Registro Rupestre}

Os grafismos rupestres compreendem os registros (pinturas, desenho ou gravuras) deixados pelo homem pré-histórico em paredes de abrigos, grutas, cânions e blocos rochosos isolados. São vestígios elaborados sobre superfícies rochosas que não podem ser transportadas (PROUS 1992).

Nas formulações dos seus postulados teóricos, os grafismos rupestres tiveram, inicialmente, influência da História da Arte. Eram interpretados como forma de representações artísticas e mágicas ou animistas. Seu estudo direcionavase para a interpretação do significado, incorrendo-se, Para alguns pesquisadores, essa abordagem artística se distanciava da unidade cultural em que foi produzida, ficando geralmente fora do contexto arqueológico.

A partir da abordagem estruturalista dos trabalhos de Leroi-Gourhan e Annete Laming-Emperaire, na década de 1970, os registros passaram a ser analisados como uma linguagem simbólica, relacionada a um contexto de comunicação, realizado através das imagens que poderiam ser entendidas a partir da organização do espaço pictural de cada sítio. Partindo-se das análises dos tipos de grafismos selecionados para serem representados, a forma de apresentação e os tipos de arranjos, foram reconhecidos códigos específicos situados no tempo e espaço, fazendo parte de um modelo referente à prática social dos grupos.

$\mathrm{Na}$ área do Parque Nacional Serra da Capivara, os grafismos rupestres compõem parte da concentração (visual) de vestígios arqueológicos, sendo um documento, ao que tudo indica, referente à vida das populações que viveram na préhistória.

A equipe franco-brasileira que chegou à região na década de 70 do século passado sistematizou as pesquisas para o entendimento das manifestações gráficas, contextualizando-as com o material de escavação e também realizando um ordenamento cronológico dos padrões de registro rupestre, com datações absolutas e relativas. Os estudos reforçaram também a hipótese de que a região foi habitada por diferentes populações a partir de aproximadamente 100.000 AP.

Dentre as pesquisas sobre pinturas rupestres na área arqueológica, tomamos como referência as de Guidon (1984), que analisou os sítios abrigos da Serra da Capivara. Outro trabalho, também de Guidon (1985), construiu um ordenamento preliminar hipotético para reconhecimento das identidades culturais incluídas em áreas nucleares de ocupação. Os conjuntos de grafismos foram, dessa forma, categorizados em classes.

A classificação de referência é a Tradição; sua definição parte das semelhanças tipológicas encontradas entre unidades sociologicamente definidas a partir dos padrões da cultura material arqueológica. A classificação de vestígios arqueológicos em Tradição serve não somente às pinturas ou gravuras rupestres, serve também para definir horizontes culturais a partir de vestígios cerâmicos e da indústria lítica. 


\section{Colonialismo, Saberes e Fronteiras epistêmicas}

Pessis (1987), estudando o interior da tradição Nordeste, reconheceu, a partir do ordenamento preliminar, a construção de indicadores qualitativos e quantitativos, elaborados para classificar os grafismos e conseguir obter informações, objetivando segregar identidades dos grupos pré-históricos.

A abordagem proposta, no presente texto, coaduna-se com o entendimento de que os grafismos rupestres do Parque Nacional Serra da Capivara são parte de um sistema de comunicação social, sendo entendido junto a parâmetros da identificação de traços essenciais e secundários na categorização das figuras, observando as técnicas na fabricação das pinturas, a apresentação gráfica, a instalação das figuras no espaço da mancha gráfica, a profundidade em algumas cenas e as sobreposições. Sendo assim, os conjuntos desses elementos podem ser indicativos de escolhas culturais de determinados grupos.

\section{Categoria de Análise em Pinturas Rupestres}

Nas pesquisas já desenvolvidas na região do parque, foram definidas categorias preliminares de análise do registro rupestre: Grafismos puros, que correspondem a figuras não reconhecíveis (abstratas); Grafismos de composição, que são representados por figuras que podem ser reconhecidas, sejam antropomorfos, zoomorfos e fitomorfos; Grafismos de ação, que são representados a partir dos grafismos de composição, que formam um conjunto gráfico com cenas compostas de atributos (adornos, armas, vestimentas) que compõem a cena de ação do painel rupestre (PESSIS 1992). Os registros rupestres são estudados de acordo com métodos que possibilitam estabelecer um padrão de apresentação social previamente estabelecido, que são constituídos de identidades gráficas. As identidades gráficas, por sua vez, são compostas por um conjunto de características que permitem atribuir a um conjunto de grafismos uma determinada autoria social (PESSIS 1992).

Partindo da segregação de características técnicas, temáticas e cenográficas, foi possível diferenciar grupos pré-históricos e fazer um posicionamento cronológico, sendo uma forma de definir as características próprias em que os autores se inseriam.

Os grafismos rupestres no Nordeste e em parte do Brasil foram ordenados em classes primeiras, chamadas de Tradição. As Tradições foram estabelecidas pelos tipos de grafismos representados e pela proporção relativa que esses guardam entre si (GUIDON 1989). Eles correspondem a uma síntese de todas as manifestações gráficas, podendo reconhecer identidades culturais (PESSIS 1992).

As Subtradições, por seu turno, são classes derivadas da Tradição que possuem um grau mais específico no âmbito da pesquisa. São estabelecidas segundo critérios ligados à diferença na apresentação gráfica de um mesmo tema e à distribuição geográfica em que estão inseridas.

O estilo é a unidade básica a ser segregada no interior de um conjunto gráfico para que se reconheça o perfil cultural dos grupos pré-históricos; também 
se define pela técnica de manufatura e pela variação na forma de apresentação gráfica. O estilo é a classe mais particular que se origina da evolução do interior de uma subtradição, sendo a percepção da transparência da modificação de procedimentos técnicos e temáticos, podendo ser entendido a partir de variáveis cronológicas (PESSIS, 1992). Nesse sentido, uma das temáticas observadas por nós nos trabalhos de campo que realizamos e nas consultas laboratoriais, é a da guerra.

\section{O estudo arqueológico dos conflitos sociais}

Nos últimos anos, os estudiosos têm demonstrado interesse crescente em explorar o uso da cultura material para estudar conflitos e lutas sociais, assim como na maneira como a interpretação do passado é construída pelas concepções modernas. Conflitos no passado e na sua interpretação constituem preocupações cada vez mais atuais. A sociedade caracteriza-se, sempre, pelo conflito e, a partir de uma epistemologia dialética, a experiência dos povos do passado é considerada como parte de um confronto constante entre atores sociais. A História das sociedades dividas por classes implica o estudo da apropriação de excedentes, assim como da exploração que engendra conflitos abertos e contradições internas na sociedade e das forças de dominação e resistência. A interpretação desses conflitos é maleável e subjetiva e podemos interpretar o passado como um conjunto de textos complexos, formando um discurso.

Se o conflito e a subjetividade fazem parte tanto da evidência quanto de sua interpretação, é inevitável a multiplicidade de interpretações e não se pode evitar tomar posições. Há diferentes maneiras de conhecer o passado e devemos afrontar a questão de quem pode saber e de quem pode participar no processo de invenção e ressignificação do passado. Neste contexto, trataremos, neste capítulo, dos estudos arqueológicos sobre os conflitos durante a ditadura militar no Brasil (19641985), com um estudo de caso, visando, também a apontar as perspectivas de pesquisa. O estudo da cultura material pode ser um poderoso instrumento na análise das histórias subalternas e na transferência de poder para os próprios agentes sociais e as controvérsias sobre a interpretação dos mecanismos materiais de repressão fornece um bom exemplo da relevância do estudo do passado para a sociedade em geral. Como costuma acontecer com estudos científicos, este capítulo levanta tantas questões quanto propõe respostas, mas, antes que apresentarmos soluções aparentemente corretas, preferimos incentivar uma discussão pluralista do tema.

Quando se busca descrever e interpretar as culturas do passado, convém incorporar o estudo tanto de textos e relatos orais, como de artefatos, o que é particularmente relevante no estudo da repressão no Brasil recente. Os dados textuais, orais e materiais podem ser encarados como interdependentes, complementares e contraditórios, ao mesmo tempo. Neste contexto, para lidar com a tarefa de interpretar o conflito no interior da sociedade impõe-se uma abordagem interdisciplinar que combine análise textual, oral e artefatual, com aportes sociológicos e antropológicos, entre outros. 


\section{Colonialismo, Saberes e Fronteiras epistêmicas}

O conflito tem sido, tradicionalmente, interpretado pelos grupos sociais dominantes. Até a década de 1960, os arqueólogos voltavam-se quase que de forma exclusiva para os ricos e famosos, o que contribuía para a manutenção e reforço de ideologias conservadoras. Gradualmente, os arqueólogos começaram a seguir seus colegas nas Ciências Humanas e Sociais em seu estudo dos grupos subordinados e o estudo das evidências materiais dos grupos subalternos permitiu um acesso mais amplo aos grupos sociais pouco representados no registro escrito. Ainda que alguns estudiosos com pouco conhecimento da cultura material tenham questionado abertamente a capacidade de a Arqueologia poder contribuir para o conhecimento do passado, diversos livros e artigos publicados nos últimos anos confirmaram que a evidência material é de particular importância para a compreensão da complexidade dos conflitos sociais.

Como interpretar o conflito social depende, de maneira direta, de como se entende a própria sociedade, interpretada pelos estudiosos, tradicionalmente, como entidades homogêneas e bem delimitadas. Esta noção, no estudo da cultura material, deriva da definição clássica criada por Vere Gordon Childe: "a cultura é uma herança social; corresponde a uma comunidade que compartilha instituições e modo de vida comuns [ênfase acrescentada]". Esta definição implica harmonia e unidade no interior da sociedade, um compartilhar de interesses e, portanto, a ausência do conflito. As raízes desta compreensão da vida social encontram-se, em grande parte, em Aristóteles e sua definição de sociedade como koinonia, ou seja, como uma parceria (cf. Aristóteles, Política 1252a7). Compartilhar valores em uma cultura homogênea significa aceitar características e tradições comuns a todos (cf. Aristóteles, Politica 1328a21).

A homogeneidade é um conceito originário dos movimentos nacionalistas e capitalistas e em direta oposição a uma abordagem internacionalista. As culturas, assim como as nações, foram vistas pela ideologia burguesa como entidades homogêneas e delimitadas e a História passou a ser concebida como o produto das ações e eventos associados a tais entidades homogêneas. A busca burguesa pela solidariedade nacional tem sido posta em questão desde Marx e, particularmente nos últimos anos, pelos críticos das interpretações da sociedade como entidades baseadas antes na solidariedade do que no conflito.

Neste contexto, o conceito de cultura arqueológica pode ser entendido. Complexos materiais fechados e homogêneos são interpretados como o produto de grupos do passado porque, diz-se, as pessoas dentro de tais grupos compartilhavam um conjunto de normas prescritivas de comportamento que eram aprendidas em tenra idade e, portanto, produziam uma cultura comum. A própria noção de doutrinação infantil inspira-se no uso das escolas na construção das identidades nacionais modernas, em um perspectiva burguesa, como no notável caso da França após a Revolução Francesa. As entidades arqueológicas são interpretadas da mesma forma, como unidades orgânicas equivalentes às nações burguesas. Contudo, contradições e conflitos sociais só são possíveis, em termos epistemológicos, se a 
sociedade for heterogênea e a dialética entre homogeneidade e heterogeneidade sociais torna-se compreensível neste contexto.

A generalização, portanto, implica homogeneização e observa-se uma crescente insatisfação com o uso de abordagens normativas na interpretação da vida social. A natureza holística, monolítica de culturas e sociedades tem sido questionada tanto por estudos empíricos como teóricos, nas últimas décadas. Homogeneidade, ordem e limites têm sido associados ao pressuposto a priori que a estabilidade caracteriza as sociedades, antes que o conflito, uma concepção claramente conservadora e ahistórica. No entanto, um número crescente de dados e um estudo crítico do pensamento social têm desafiado este ponto de vista tradicional, passando a considerar a sociedade como heterogênea, com construções conflitantes sobre identidade cultural. Heterogeneidade, fluidez e mudanças contínuas implicam a existência de múltiplas entidades sociais, sempre em mutação na sociedade (Funari 2003b; Oliveira 2004).

\section{A guerra como fator social}

A guerra é um fenômeno humano. Não se pode afirmar precisamente como e quando ela surgiu no passado remoto da humanidade. Tampouco se pode presumir a que "necessidades" existenciais (biopsíquicas ou sociais) ela correspondeu originalmente. Até onde alcança a investigação empírica - indutiva, através da reconstituição arqueológica, da reconstrução histórica e da observação direta - a guerra nos é apresentada como um fator social, no sentido restrito de existir como uma das instituições sociais incorporadas a sociedades constituídas (FERNANDES, 1970).

Frequentemente, por vivermos em sociedades, lidamos com sistemas comportamentais e gestuais (ações instintivas, reprodutividade, agressividade). Em sua maioria, são bastante complexos e seus processos, realizados de forma teleonômica unitária à sobrevivência, são legitimados de acordo com suas funções e motivações. Os padrões motores verificados durante as atividades derivam das mais variadas funções que são transmitidas em ações e nos gestos (LORENZ 1995).

Já os grafismos rupestres desempenharam funções de acordo com convenções simbólicas, acontecimentos e atividades essenciais; são dotados de padrões gestuais e comportamentais teleonômicos, sendo necessários à vida dos indivíduos (PESSIS 2003).

No contexto do comportamento de agressão e de reprodução, acumulamse necessidades de símbolos que provoquem, respectivamente, sentimentos diferentes, como medo e respeito; tal dimensão se projeta dentro do próprio grupo ou para fora dele, tal como assinalou Leroi-Gourhan (1965).

Enquanto o adorno possui, sobretudo, um valor étnico, associado à assimilação de uma personalidade social fixa, suas insígnias são específicas de um território com seus significados. A função do vestuário e da sua decoração, por sua vez, reporta-se a múltiplos aspectos da organização social - metaforicamente, como 


\section{Colonialismo, Saberes e Fronteiras epistêmicas}

entre os pássaros, assegura simultaneamente a distinção da espécie e a dos sexos (LEROI-GOURHAN 1965).

A guerra, com efeito, é uma atividade extraordinariamente bem-sucedida. Num mundo dominado por posses materiais - sejam mercadorias, terras ou recursos naturais - uma população pode conseguir para si uma enorme vantagem por meio de uma vitória militar sobre outro grupo, tal como expõem Leakey e Lewin (1996). Para Fernandes (1970), a guerra se ramifica por toda a sociedade, satisfazendo ou contribuindo para satisfazer diversas necessidades sociais. Susnik (1980), por seu turno, compreende que existiria uma formação guerreira, para defesa local e também pela necessidade ofensiva às suas vizinhanças e em fase de conquista territorial.

A demarcação entre a questão da guerra e da identidade, em essência, é o confronto com o outro. O reconhecimento da diferença é a consciência da alteridade, a descoberta do sentimento que se assegura de símbolos da cultura e capaz de esclarecer que nem tudo é o que eu sou e nem todos são como eu sou (BRANDÃO 1987).

A guerra, ainda, pode ser entendida como um conflito realizado por homens armados, geralmente com os mais diferentes motivos definidos (GUILAINE Y ZAMMIT 2002).

As cenas de guerra nos grafismos rupestres representam, em nosso entendimento, um conjunto de elementos que refletem a existência de indivíduos que estariam armados; estão, contudo, próximos a membros que provavelmente seriam da mesma sociedade, possivelmente repassando conhecimentos e saberes acerca da utilização desses elementos a outras gerações, mas que também podem ter servido a outros grupos que eles desconheciam (Figura 3).

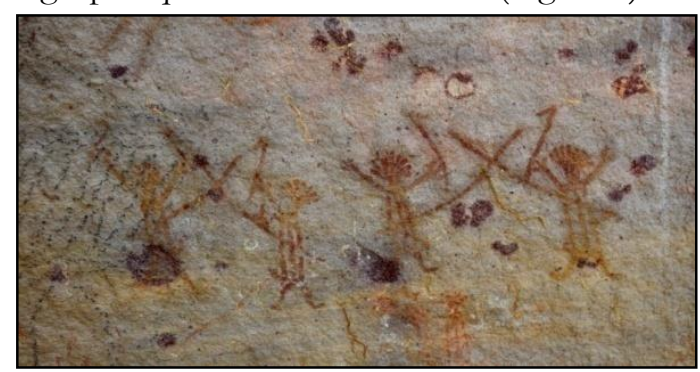

Figura 3: Cena de guerra. Toca do Vento.

Serra da Capivara. Piauí. Brasil. Fonte:

Fernando Queiroz 2017

A guerra é uma maneira de valorizar os indivíduos e de reforçar a influência e as características de uma determinada comunidade.

Nos registros arqueológicos (indivíduos mortos, armas, fortificações) se apreendem as facetas do comportamento humano ligadas aos atos de agressividade e violência resultantes, por exemplo, da ação da guerra (Figura 4). 


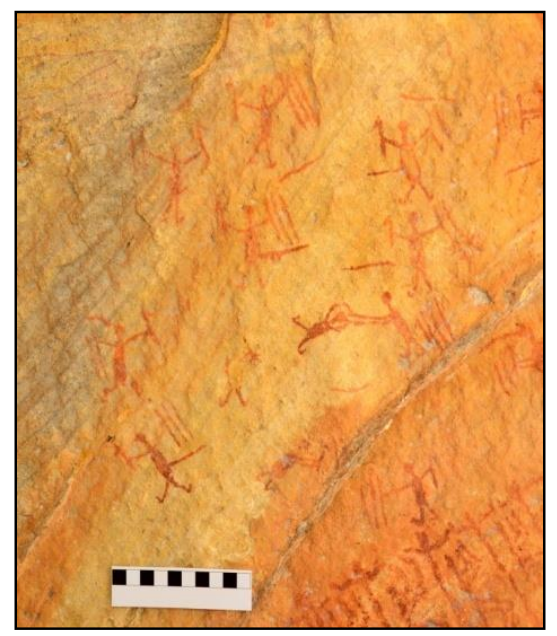

Figura 4: Cena de guerra. Toca da Extrema II. Serra da Capivara. Piauí. Brasil. Fonte: Fernando Queiroz 2017

Contudo, as fontes arqueológicas sobre formas de conflitos são bastante escassas. Além disso, dependem, muitas vezes, da frágil conservação dos restos humanos com marcas de agressão, indícios fundamentais para a reconstrução do contexto social e entendimento da progressiva complexidade dos períodos de ações violentas de determinados grupos (GUILAINE Y ZAMMIT, 2002).

Nos grafismos do paleolítico espanhol, por molde, dominam as cenas de caça, coleta, combate e dança. O realismo dos detalhes apresenta dinamismo e características da vida, do comportamento, da vestimenta e dos armamentos dos antigos habitantes da região. As cenas de guerra mostram detalhes das decorações e composições elaboradas, que permitem identificar um combate de guerreiros, com demarcações de adornos e tipos de armas (GUILAINE Y ZAMMIT, 2002).

Para amplificar nossas reflexões, recorremos às fontes de documentação, estudos etnográficos e trabalhos que contribuem para o entendimento da diversidade cultural. Em se tratando de sociedades pré-históricas, as inferências feitas em grupos vivos ou ações referentes a observações de campo, favorecem a não realização de interpretações frágeis.

Pierre Clastres (1977) afirma que a sociedade primitiva é guerreira por essência. Trata-se de algo que se pode constatar com certa universalidade, baseada em relatos etnográficos. A guerra está inserida nas infinitas variedades de sociedades primitivas conhecidas. A atividade guerreira é um atributo da sociedade e se apresenta, portanto, como função, como tarefa inscrita desde o início no horizonte que determina o ser-no-mundo. Na sociedade primitiva, o homem é, por definição, um guerreiro.

As pinturas e as manifestações gráficas dos grupos indígenas que habitavam o território brasileiro foram objetos de atenção de cronistas e viajantes, desde o primeiro século após a chegada dos portugueses; foram também objetos de 


\section{Colonialismo, Saberes e Fronteiras epistêmicas}

inúmeros estudiosos que nunca deixaram de registrá-los e de surpreender-se com essas manifestações presentes nos paredões rochosos e nos corpos dos índios, sendo, muito provavelmente, objetos utilitários em rituais (VIDAL 2000).

Os cronistas também não deixaram de relatar as diferentes guerras que ocorriam entre grupos étnicos, fazendo parte da sua dinâmica social. A dinâmica da cultura material traz um conjunto de fatos, que são prioritários à vida.

A guerra pode ser inferida também como o encontro entre grupos diferentes ou como a cisão interna de um grupo, que desencadeia o conflito, sendo proporcionada conforme as reações afetivas, seguidas de normas das relações intraétnicas. A identificação das cenas de guerra determina, no registro arqueológico, as formas de representações das relações. A presença de um chefe e de guerreiros hábeis, que são apresentados em um conjunto hierárquico, diferencia os seus membros, sendo uma forma de identificação do valor individual (Figura 5).

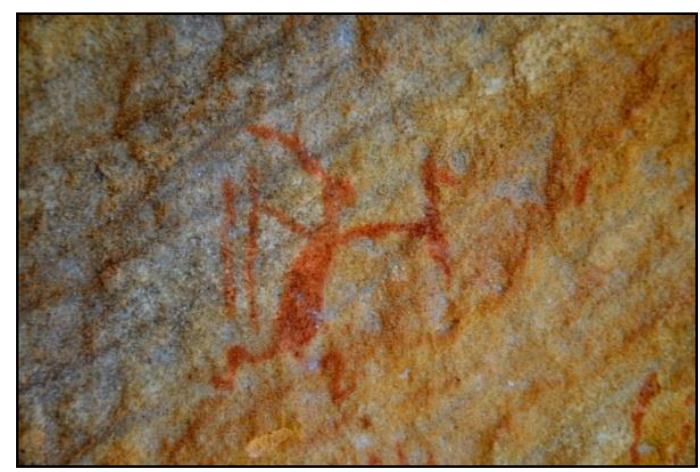

Figura 5: Cena de guerra. Toca da Extrema II. Serra da Capivara. Piauí. Brasil. Fonte:

Fernando Queiroz 2017

A concepção de guerra faz-se da conquista de uma posição hierárquica, sendo um condicionante à decoração da indumentária de todos os povos. LeroiGourhan (1965) As classes etárias não se estabelecem de uma forma constante: em determinadas sociedades, existe efetivamente uma codificação implícita ou explícita do vestuário de cada classe. As atitudes da linguagem demonstram os limites do domínio figurativo; as ações, os símbolos, apresentam os membros de uma sociedade e parte de seu universo étnico.

A concepção de decoração refere-se aos componentes do universo indígena - artefatos, animais, vegetais, espíritos, entidades míticas - e conforma-se em um recurso visual que thes propicia especificidade e identidade, caracterizada como forma da ordenação do universo. Essa ordenação representa as capacidades das mudanças e da vida social do homem (VELTHEM, 2000).

Métraux (1986), a partir de suas pesquisas etnográficas, observa que as armas são desenvolvidas com diversas finalidades: para uso no choque, de arremesso ou para combate à distância, podendo ser perfurantes ou contundentes; podem ser usadas não só na guerra, mas na caça, pesca e ritos. Já Chiara (1986) 
comenta que a projeção das armas varia de morfologia e de ornamentos, tornandose objetos de classificações tipológicas e servindo como diferenciador cultural.

As classificações realizadas por Chiara e Métraux caracterizam os seguintes tipos de armas utilizadas por populações indígenas ainda vivas: zarabatana,lança, azagaia, borduna, boleadeira, propulsor de dados, funda, machado de guerra, flecha. É possível serem encontradas outras nomenclaturas e diferentes formatos de armas, dependendo do local e da cultura a ser estudada.

As análises das armas pela etnografia permitem detectar influências intertribais e migrações, e também aferir os detalhes técnicos de confecção de artefatos. Na pintura rupestre, por seu turno, os diferentes objetos estão associados às figuras humanas; a ausência de representações de arcos e flechas faz supor que os grupos ocupantes da área da Serra da Capivara, em tempos imemoriais, não utilizavam esse tipo de arma. Nessa região, o artefato mais evidenciado é o propulsor (CHIARA 1986).

\section{Algumas considerações sobre os guerreiros da serra}

Este texto procurou um direcionamento micro analítico na caracterização das cenas de guerras, que foram definidas a partir do dinamismo presente em sua composição e do envolvimento dos indivíduos na ação gestual que reflete a caracterização do combate.

Os antropomorfos observados nas cenas de representações de guerra que identificamos nos sítios arqueológicos pesquisados aparecem de modo análogo a guerreiros. Apresentam-se em movimentos gestuais, entendidos como de ataque e defesa, como também os componentes que erguem os seus objetos de mão.

A ação deliberada de cada indivíduo está marcada na flexão e posicionamento das pernas, postura do corpo (ereta, inclinada, curvada) e o movimento dos braços com as armas, diferenciando a perspectiva de cada indivíduo na construção da cena. A ação gestual dos envolvidos resulta em áreas específicas do corpo atingido pelos oponentes no uso de suas armas.

As imagens rupestres que apresentamos podem levar os leitores a inferirem outras possibilidades de interpretações. Nossas reflexões sobre o tema da guerra (ou guerras) praticadas na região da Serra da Capivara muito antes da conquista europeia, contudo, estão relacionadas com nossas análises de campo e de laboratório. Além disso, baseamo-nos em relatos etnográficos que indicam essa prática, mesmo que ritualizada, entre os povos originários do Brasil.

Temos como desejo final do presente artigo que, a partir de nossas reflexões, seja possível observar que somos os mesmos humanos, ou seja, desde há milhares de anos, temos as mesmas condições mentais. Além de termos muitas práticas similares às praticadas por nossos ancestrais, como as próprias guerras. 


\section{Agradecimentos}

Agradecemos a Niède Guidon, Gabriela Mart[in, Anne Marie Pessis, Águeda Vilhena Vialou e Nanci Vieira de Oliveira. . Devemos mencionar, ainda, o apoio institucional da UFAM, UESPI, Unicamp, CNPq, e FAPESP. A responsabilidade pelas ideias restringe-se aos autores.

\section{REFERÊNCIAS}

BRANDÃO, C.1987. Identidade e Etnia: Construção da pessoa e resistência cultural. São Paulo: Editora Brasiliense.

CLASTRES, P. 1977. Arqueologia da Violência. Lisboa: Edições 70.

FERNANDES, F. 1970. A função social da guerra na sociedade tupinambá. São Paulo: Livraria Pioneira Editora.

CHIARA, V. 1986. Armas: bases para uma classificação. Em Suma etnológica brasileira, editado por D. Ribeiro, pp. 117-138. Vozes, Petrópolis.

GUIDON, N. 1984. Arte Rupestre: Uma síntese do procedimento de pesquisa. Arquivos do Museu de História Natural. Belo Horizonte: UFMG, v. 6-7, p.341-352.

GUIDON, N. 1985. Arte pré-histórica da área arqueológica de São Raimundo Nonato: Síntese de Dez Anos de Pesquisa. Revista CLIO - Série Arqueológica UFPE 7:3-80.

GUIDON, N. 1989. Tradições Rupestres da Área Arqueológica de São Raimundo Nonato, Piauí, Brasil. Revista CLIO - Série Arqueológica UFPE5:5-10.

GUILAINE, J.; J. ZAMMIT. 2002.El Camino de La Guerra: la Violencia en la prehistoria. Editora Ariel Prehistoria, Barcelona.

LEROI-GOURHAN, A. 1965. O gesto e a palavra 2 - memória e ritmos. Edições 70, Lisboa.

LEAKEY, R.; R. LEWIN. 1996. O Povo do Lago - O bomem: Suas Origens, Natureza e Futuro.UNB, Brasília.

LORENZ, K.1995.Os Fundamentos da Etologia. Tradução de Pedro Melo Cruz e Carlos C. Albert. Universidade Estadual Paulista, São Paulo.

MARTIN, G. 1984. Amor, Violência e Solidariedade no Testemunho de Arte Rupestre Brasileira. Revista CLIO - Série Arqueológica UFPE 6: 27-37.

PESSIS, A. M. 1987. Art rupestre prehistorique: Premiers registres de la mise en scene. 502 f. Tese (Doutorado de Estado). Université de Paris X, Nanteire.

PESSIS, A.M. 1992. Identidade e Classificação dos Registros Gráficos Pré-históricos do Nordeste do Brasil. Revista CLIO - Série Arqueológica UFPE 8: 35-68.

PESSIS, A.M. 2003. Imagens da Pré-História. Parque Nacional Serra da Capivara. FUMDHAM/PETROBRÁS,A\&A Comunicação, São Paulo.

PROUS, A. 1992. Arqueologia Brasileira. Universidade de Brasília, Brasília.

SUSNIK, B. 1980. Los Aborigenes del Paraguay: Etnohistória de los Guaranies. Época colonial. Assunción: Museu Etnográfico "Andres Barbedo".

VELTHEM, V. 2000. Das Cobras e lagartas: A iconografia Wayana. Em Grafismo Indigena, organizado por L. Vidal, pp. 19-33. Editora da Universidade de São Paulo, São Paulo.

VIALOU, Á.V. 2006. Pré-bistória do Mato Grosso. v. 2. USP, São Paulo.

VIDAL, L. (org.). 2000. Grafismo Indígena: Estudos de antropologia estética. Editora da Universidade de São Paulo, São Paulo.

VILLAVERDE, V. 2002. La cova dels cavales en el barranc de la valltorta. Monografia Del Instituto de arte. Museu de la valtona.

Childe, V.G. 1935Changing Methods and Aims in Prehistory, Presidential Address for 1935. Proceedings of the Prehistoric Society 1:1-15. 
Duarte, P. 1970 Fontes de pesquisa pré-histórica, Estudos de Pré-História Geral e Brasileira, São Paulo, IPH/USP, 374-442.

Duarte, P. 1994Paulo Duarte e o Instituto de Pré-História, Idéias, Campinas, 1,1, 155-179.

Funari, P.P.A 2002 Class interests in Brazilian archaeology, International Journal of Historical Archaeology, 6,3, 2002, pp.209-216.

Funari, P.P.A. 2003a Dictatorship, democracy, and freedom of expression, International Journal of Historical Archaeology, 7, 3, 2003, 233-237.

Funari, P.P.A. 2003b História, contradições e conflitos, in Marxismo e Ciências Humanas, São Paulo, Ed. Xamã/Cemarx/FAPESP, 2003, pp. 101-106, ISBN 857587011-4.

Funari, P.P.A., Zarankin, A., Stovel, E. 2005 (eds) Global Archaeological Theory, Contextual voices and contemporary thoughts, Nova Iorque, Kluwer/Plenum.

Oliveira, N.V. 2004 Arqueología e Historia: estúdio de um poblado jesuítico em Rio de Janeiro, in Arqueologia Histórica em América del Sur, Los desafios del siglo XXI, P.P.A. Funari \& A. Zarankin (eds), Bogotá, Uniandes, 73-91.

\section{Lista de Figuras}

Figura 1: Cena de guerra. Toca do Conflito. Serra da Capivara. Piauí. Brasil. Fonte: Fernando Queiroz 2017.

Figura 2: Cena de guerra. Toca do João Arsena. Serra da Capivara. Piauí. Brasil. Fonte Direta 2017

Figura 3: Cena de guerra. Toca do Vento. Serra da Capivara. Piauí. Brasil. Fonte: Fernando Queiroz 2017

Figura 4: Cena de guerra. Toca da Extrema II. Serra da Capivara. Piauí. Brasil. Fonte: Fernando Queiroz 2017

Figura 5: Cena de guerra. Toca da Extrema II. Serra da Capivara. Piauí. Brasil. Fonte: Fernando Queiroz 2017 